\title{
Notas para pensar uma leitura... o aprendizado da vontade criadora de Zaratustra
}

Notes to think of reading... The learning of Zarathustra's creative will

https://doi.org/10.34112/2317-0972a2016v34n66p31-45

MARia dos Remédios De Brito ${ }^{1}$

RESUMO: O presente ensaio objetiva destacar breve nota sobre o primeiro estágio da segunda parte da obra Assim falou Zaratustra, de Friedrich Nietzsche. O fio condutor de leitura será a ideia de vontade criadora. $\mathrm{O}$ personagem central, Zaratustra, pretende reeducar os seus discípulos pelo excesso de amor e busca ensinar-lhes a mais alta afirmação da vida, exigindo do criador um exercício trágico de criação. Então, criar para a superação é inseparável da destruição, da dor e do sofrimento. Para fomentar esse exercício criador, faz-se fundamental a coragem de olhar para o abismo. Zaratustra promove a reeducação dos seus discípulos, ao mesmo tempo em que faz sua própria abertura para o aprendizado de si mesmo.

PALAVRAS-CHAVE: Vontade criadora; Zaratustra; discípulos.

ABSTRACT: The article intention is to highlight a note in the first stage of the second part of the work Thus Spoke Zarathustra, by Friedrich Nietzsche. This reading is guided by the idea of creative will. The main character, Zarathustra, intends to re-educate his disciples through love and tries to teach them the highest affirmation of life, demanding a tragic exercise of creation from the creator. Therefore creating for overcoming is inseparable from destruction, pain and suffering. In order to stimulate this creative exercise, the courage to

1. Universidade Federal do Pará, Belém, PA, Brasil. 
look into the precipice is essential. Zarathustra promotes the rehabilitation of his disciples while opening to the learning of himself.

KEYWORDS: Creative will; Zarathustra; disciples.

"Criar - eis a grande liberação do sofrer, e o que torna a vida leve. Mas, para que haja o criador, é necessário sofrimento, e muita transformação."

(NIETZSCHE, 2011, p. 82)

1.

A obra Assim falou Zaratustra: um livro para todos e ninguém demarca o terceiro período filosófico de Nietzsche e condensa os principais temas de seu pensamento filosófico. Ela não se torna importante somente por sua filosofia madura, nem por apresentar uma linguagem extremamente refinada e uma estilística avançada, mas, principalmente, porque apresenta um pensamento demolidor e construtor, que exercita a base mais afirmativa do pensamento de Nietzsche.

A perspectiva de leitura dessa obra fundamental é que ela tece uma especial perspectiva formativa do personagem central, Zaratustra. Com isso, ela não pode ser negligenciada na educação, tampouco pelos pesquisadores interessados na filosofia da educação e na ampliação interpretativa do pensamento filosófico-educativo deste pensador.

Os elementos constitutivos de sua ação formativa se configuram pela vivência, pela tensão, pela contradição e pelo movimento, bem como se observam o alto e o baixo, o fogo e a cinza, a plenitude e o declínio, a abundância e o vazio. Com esses elementos é que Zaratustra traça a sua crítica à conservação e à tradição. Os ensinamentos de Zaratustra (que não são imposições, mas interpretações, sinais, indícios, signos) buscam compreender o indivíduo como criador, capaz de exercitar a singularidade, o que lhe é próprio e particular; buscam a potencialidade da força criadora, a fim de que o indivíduo se mova para a superação de si mesmo - questões esquecidas por algumas perspectivas tradicionais de formação. No entanto, a vontade criadora não é um limite, mas autossuperação, envolvendo todo o aspecto dinâmico e trágico da vida.

Assim, o mosaico zaratustriano é uma contestação de toda vida niilista e reativa da cultura do seu tempo. Em torno da tarefa crítica e da ruptura da tradição, podese compreender o esforço crítico, demolidor, criador e afirmativo da obra e do 
personagem central, o que nos permite pensar outra ordem de argumentação. $O$ pensamento filosófico de Zaratustra quer penetrar de modo mais fundo em todas as esferas de negação da vida, para chegar à elevação de uma filosofia afirmativa e experimental, dando perspectiva para o como se tornar o que se é, que não é querer uma essência, uma natureza, uma determinação fechada, ou prender-se em si mesmo, em seus valores e costumes. $O$ como se tornar o que se é é aberto para um processo constante de formação que demanda despojamento, vivências para além do que seja dado e definido. Dessa maneira, o conteúdo filosófico referenciado leva-nos ao enriquecimento, dando a possibilidade para que cada um, por meio do aprendizado de Zaratustra, se lance à procura de sua própria retomada, de seu próprio cume, para poder ser o que é. Há um convite ousado e corajoso para o indivíduo tomar sua formação como experimento altamente criativo.

Zaratustra quer sentir a vida e o mundo sendo atravessados sem receio, sem medo, pois assim requer esse tipo afirmativo por excelência, para dar ao indivíduo a capacidade de criar e festejar sua própria capacidade de elevar-se, sem paradas. Por isso, procura emergir de dentro dos valores da tradição, no intuito de retirar todos os véus e os seus disfarces, para destacar que nesse tipo cultural se estabelece a vontade afirmativa do asno, do apenas dizer sim, sem saber dizer não; e, nesse sentido, não cria, apenas conserva, ou seja, seu sim não é criador. Porém, para a conquista de estabelecer, criar, derrubar e novamente construir valores, avaliações, é fundamental saber dizer não mesmo ao dever, mas também saber dizer um sim criador; para tanto, é necessário derrubar ídolos, deuses e tudo que nega o poder criador do homem.

Com isso, ao dialogar com a negatividade, não pretende esvaziar-se, escamotearse, já que é sentindo a fadiga, o nojo, a reatividade (niilismo) que procura dar voz ao grito criador. $O$ que se segue serão algumas anotações da segunda parte da obra, que, tomando como fio condutor a ideia de vontade criadora como outra linha do aprendizado de Zaratustra, mostra como o personagem central vivencia o seu segundo declínio ${ }^{2}$ e o que ele retira de formativo para si mesmo.

2. "[...] voltar para meio dos homens não mais significa voltar para a grande cidade, para a praça do mercado, para todos. Ao fazer a ação da segunda parte se passa 'nas ilhas bem-aventuradas', Nietzsche está salientando a importância que o indivíduo heroico continua a merecer no pensamento de Zaratustra depois do fracasso do 'Prólogo' e a descoberta de que alguns privilegiados deverão substituí-los no caminho para o superhomem” (MACHADO, 1997, p. 83). 
2.

Depois de grandes desertos solitários, na segunda parte da obra Assim falou Zaratustra ${ }^{3}$, Nietzsche mostra o segundo "declínio" de Zaratustra. Apresentando-se "amadurecido" e "transformado", Zaratustra pretende a reeducação dos discípulos por meio da sua volta junto a eles e da sua própria reeducação. Destacando mais uma vez o niilismo e sua incompatibilidade com a perspectiva do super-homem (problemática já posta no prólogo da obra), fala sobre a vontade de potência como a sabedoria da vida. Questões profundas que vão sendo apresentadas no transcorrer de seu percurso tratam da problemática relativa à vida, ao tempo, ao devir, à promessa da redenção fora do tempo. Retoma algumas discussões da primeira parte, insiste em fazer a crítica aos "valores religiosos, morais e gnosiológicos decorrentes da visão cristã de mundo" (MACHADO, 1997, p. 82), pois entende que esses impedem que o indivíduo se torne maior e acabam enredando-o numa teia viciosa de depreciação. Porém, se isso está entrelaçado com as relações complexas que passam pelo formativo, em que tanto insiste Nietzsche, ele toma posição, na seção "Do país da formação", como forma de evidenciar a necessidade da transformação da cultura, do indivíduo e dos valores vigentes.

Em certa altura de seus discursos, há um outro movimento formativo, em que, ao deixar de discursar, canta e mostra uma outra faceta do seu aprendizado, definindo e pontuando uma outra guinada interpretativa de si mesmo, de sua compreensão de vida. Notam-se a metamorfose e a tensão do personagem, que se encontra no movimento para como se tornar o que se é. O seu aprendizado, efetivamente, é construído em rupturas, com desafios profundos, que mexem com sua intimidade, com seus valores, com suas atitudes. Não é à toa que, no decorrer do seu aprendizado,

3. Para Machado (1997, p. 81), "a segunda parte do livro, que apresenta a segunda volta de Zaratustra para meio dos homens, é constituída por três estágios de crescente importância. $\mathrm{O}$ primeiro é a reeducação dos discípulos através de um ensino em continuidade com a primeira parte: expõe, inicialmente, a crença em Deus, considerando-a causa do niilismo, incompatível com o super-homem e a vontade criadora; por abolir o tempo e o devir com a doutrina do imperecível e a promessa de redenção fora do tempo; critica, em seguida, os valores religiosos, morais e gnosiológicos decorrentes da visão cristã de mundo... O segundo estágio apresenta, pela primeira vez, Zaratustra atraído [...] pelo aspecto noturno, sombrio, tenebroso [...] Finalmente, o terceiro estágio introduz o tema do eterno retorno, situando a irreversibilidade do tempo e a existência do passado não só como limite à vontade de potência, mas também como desafio que deve ser levado em conta ao se pensar uma autêntica redenção”. Para essa breve anotação, foram tomados como imagem o primeiro estágio dessa parte e sua ligação com a ideia de vontade criadora. A leitura completa dessa passagem pode ser encontrada em outros textos publicados em periódicos nacionais. 
se mostra preocupado, ansioso, insatisfeito; os desafios tornam-se mais presentes, o que o leva a ser mais exigente consigo mesmo.

A segunda parte da obra apresenta Zaratustra em crise em alguns momentos, e isso pode ser entendido como um avanço educativo e não como retrocesso, pois não compreende com exatidão os enredamentos dos problemas que lhe aparecem e, mesmo não sabendo solucioná-los, não se sente acuado, identificando que o formativo passa pelo desconhecido daquilo que se apresenta para nós. Não é possível entender tudo, ter para tudo respostas e soluções, e reconhecer isso é mostrar a sua dignidade. Por último, ele vai conduzindo a si mesmo e ao seu leitor para a introdução da temática do eterno retorno. E com ele eclode uma profunda dramaticidade, diante do seu aprendizado, o que não será ponderado neste ensaio.

3.

Após deixar os discípulos, retorna novamente à solidão, como uma espécie de busca de si mesmo, pois somente a personalidade heroica (e aqui se percebe o quanto Zaratustra a valoriza) é capaz de fazer esse trabalho. Recolhendo-se na caverna ou na montanha, sua sabedoria cresce, torna-se abundante, e ele pretendente doá-la. Por isso, a segunda parte caminha juntamente com os ensinamentos da primeira, fazendo-nos lembrar do início do prólogo.

Floresce em sua solidão, se enche de amor, mostra-se impaciente, sofre, pois está distante daqueles que ama - os discípulos -, e, por outro lado, há uma espécie de desejo de furtar-se da companhia dos homens. Apresenta-se mais cuidadoso, motivado pelo excesso, pois luas e noites foram passadas, e cada vez mais o seu amor se torna maior. Deseja doar, compartilhar sua alegria e felicidade, quer ficar junto dos seus pares, tanto dos que ama como dos que não ama também - dos seus inimigos. Em certa manhã, é despertado por um sonho, no qual é presenteado com um espelho por um menino ${ }^{4}$. Zaratustra, ao olhar-se nele, não vê a sua imagem, mas uma careta e o riso de um diabo. $\mathrm{O}$ sonho é compreendido como um aviso: sua doutrina corre perigo e há a possibilidade de perder seus amigos. Diz: "O joio quer ser chamado de trigo" (NIETZSCHE, 2011, p. 79), seus inimigos querem desfigurar sua doutrina. Levanta-se de um salto, mas não como alguém assustado, como se procurasse ar, porém como um vidente. Com a aurora, seu rosto brilha e mostra uma grande felicidade. Ele, então,

4. Para a seção "Do menino e o espelho", Nietzsche havia previsto "A segunda aurora”. 
pergunta aos seus animais, à águia e à serpente, se acaso não estaria “transformado" e se para ele não viera a ventura. Sente-se preparado para descer e dar presentes, como outrora. Nessa altura do seu aprendizado, ele não está mais no mercado, na cidade sem nome, nem na cidade chamada "A vaca malhada", pois: "Novos caminhos sigo, uma nova fala me vem; como todos os criadores, cansei-me das velhas línguas. Meu espírito já não deseja caminhar com solas gastas" (NIETZSCHE, 2011, p. 80). Quer navegar em outros mares, por isso, encontra-se feliz, "nas Ilhas bem-aventuradas," sem ter receio dos seus inimigos, porque foram eles que lhe permitiram quebrar o ensejo de sua solidão, e Zaratustra lhes agradece por prodigalizar a sua sabedoria, a qual vem como um grito feroz e violento, pois, "em verdade, como uma tormenta chegam a minha felicidade e minha liberdade" (NIETZSCHE, 2011, p. 81). É com a voz leonina que Zaratustra se mostra, como aquele que pretende negar todos os embustes que lhe foram impostos: "Ah, se a minha leoa sabedoria soubesse rugir meigamente" (NIETZSCHE, 2011, p. 81), mas ela é violenta como uma onda forte que pretende dizimar o desamor, a vingança, a igualdade, a compaixão, as virtudes do medo, pois tem certo receio de que seus companheiros se afastem dele. Contudo, o caminho da sabedoria está na transformação do asno, do sim resignado, para um "eu quero", por isso diz: "Minha selvagem sabedoria ficou prenhe em montes solitários; em ásperas pedras deu à luz o seu filhote mais novo. [...] No relvado macio de vossos corações, meus amigos! - no vosso amor ela quer aninhar seu favorito" (NIETZSCHE, 2011, p. 81). O momento aniquilador do pensamento retorna, o martelo criador se posiciona, é hora de bater no interior da vontade de nada:

Mas para o ser humano sempre me impele minha vontade criadora; assim o martelo é impelido para a pedra. Ó humanos, na pedra dorme uma imagem, a imagem de minhas imagens! Ai que ela tenha de dormir na mais dura e feia das pedras. Agora meu martelo investe furiosamente contra a sua prisão. A pedra solta estilhaços; que me importa? Quero completar isso: pois uma sombra veio um dia até mim! A beleza do super-homem veio a mim como sombra. Ah! meus irmãos! Que importa ainda - os deuses? (NIETZSCHE, 2011, p. 83).

O conhecimento do martelo que Zaratustra salienta é a sabedoria pela qual o homem pode tomar em suas mãos sua atividade, livrando-se de todos os grilhões,

5. Para esta seção o título previsto inicialmente era "Os deuses" (MACHADO, 1997, p. 82). 
das prisões valorativas e morais, bem como do pensamento minguante dos deuses. Assim, a figura de Deus é destacada, não como criador de tudo, última lei, mas para o super-homem, essa força que se impõe como criadora, e não deve passar de uma suposição. "Deus é uma conjectura, mas quero que vossas conjecturas não excedam vossa vontade criadora” (NIETZSCHE, 2011, p 81). O homem, mais uma vez, é enfatizado como o criador ${ }^{6}$. Não é uma suposição de um Deus que fomenta toda a criação, mas o homem através da sua atividade, do seu querer libertador, demolidor, que pode dar sentido ao mundo e à vida, de acordo com o seu teor interpretativo. Esse pensar é exigente tanto do componente crítico como da própria superação de todo conhecimento vingativo que esteja ligado ao modo de pensar do homem do mercado.

A especificidade desta frase: "Deus é uma conjectura" (NIETZSCHE, 2011, p. 81) põe o querer como vontade de criar, celebrando a criação e, ao mesmo tempo, a inseparabilidade da destruição. Nesse sentido, o homem pode conferir a si mesmo a capacidade de exercer o seu experimento e, até mesmo, fazer de Deus uma ficção. Ora, se com a imagem de Deus tudo já tinha seu destino e naturalização, com a figura do criador tudo é revirado e revisto. Pois com ele a vida e o mundo são movimentos. Com isso, torna-se apropriado dizer que a vontade criadora exerce a liberdade, esmagada pelas concepções tradicionais de mundo que tendem a aprisionar o indivíduo ou mesmo as concepções moralistas da compaixão.

Mais cauteloso, Zaratustra pretende "reeducar" os seus discípulos, chamando atenção para a crença em "Deus", nos "compassivos", nos "virtuosos", na "canalha”, nas "tarântulas 7 " e nos "sacerdotes". Zaratustra pretende ensinar aquilo que pode fomentar a mais alta possibilidade da afirmação ativa, construtiva de uma saúde vigorosa, capaz do exercício trágico da criação, destacando que só a partir do esforço

6. Para Eugin Fink (1988, p. 80), o homem criador “é o autêntico, essencial. Naturalmente que 'criador' não significa o homem do trabalho, mas o homem que cria jogando, que cria valores, que quer e possui uma grande vontade, que estabelece para si um objetivo, que ousa um novo projeto. Para o criador não existe mundo sensível já pronto no qual ele se limita a integrar-se, que ele aceite; o criador assume uma atitude original em relação a todas as coisas, estabelece novas medidas e novos pesos, dá uma forma totalmente nova à vida humana, existe de modo eminentemente 'histórico': quer dizer, como fundador".

7. Na seção "Das Tarântulas", Nietzsche se volta contra todas as correntes modernas que pregavam a democracia, o socialismo e, acima de tudo, contra o cristianismo, com suas noções de igualdade perante Deus, indo contra todas as concepções tradicionais de justiça. Nesta mesma seção ele ensaia a temática da moral dos senhores e da moral dos escravos, que vai ser explorada na sua obra Genealogia da moral (1998) e em Além do bem e do mal (1992).

8. Sobre os sacerdotes, Nietzsche se aprofunda nesta questão em seus livros posteriores a Zaratustra, em Além do bem e do mal (1992) e Genealogia da moral (1998). 
da autoformação, na deseducação desses valores, se pode caminhar para as alturas. Portanto, o homem é convidado a desaprender o que lhe foi imposto como verdade, como lei, para que possa superar-se. É assim que a Bildung zaratustriana vai para além da instrução ou da informação, ela atravessa como um contramovimento aquilo que está instaurado como norma na cultura. É no entendimento de outro sentido, de outro significado, de novos hábitos que pode haver superação de si mesmo. Dessa forma, o potencial formativo de Zaratustra é desconcertante, porque é exigente de nova postura, de um exercício forte de saber lidar com a decadência, sem que nela se possa sucumbir. Não é negando-a, mas é com ela que o homem pode fazer sua travessia. Dessa forma, ele retoma a discussão sobre os valores danificados, pois quem quer ser criador deve ser também parturiente.

Para ele próprio ser a criança recém-nascida, o criador também deve querer ser a parturiente e a dor da parturiente. Em verdade, através de cem almas percorri meu caminho, e de berços e dores do parto. Muitas vezes me despedi, conheço as pungentes horas finais. (NIETZSCHE, 2011, p. 83).

Ou seja, é com o despojamento, é com a coragem de fazer despedidas que o homem pode sempre renascer novamente. $O$ conhecimento da filosofia do martelo sofre, ao perceber que o homem vive nessa prisão. Prefere cem vezes, cem dores, que a sua vontade chegue para libertá-lo, pois não quer jamais sentir o cansaço de não querer criar, de não dar sentidos a outros valores. Então, essa vontade deve estar para longe de todos os deuses; é nesse sentido que a criação se instaura de maneira formativa em Zaratustra, tanto para ele como para nós, leitores. Porque, ao criar outras medidas, pode criar outros conhecimentos condizentes com a vida afirmativa e livre, ou seja, com outro tipo de homem. E toda essa perspectiva criativa não se fez em cima de verdades dadas - é dessa maneira que Zaratustra insiste em dizer que fez seu caminho por cem tentativas. Educa-se e se torna educador pelo exemplo, porque comunica, exercita a sua coragem e o seu posicionamento diante da vida: educa quando denuncia, se expõe, coloca em evidência tudo que parece já quase naturalizado, questiona os valores impostos como verdades, e, por fim, convoca o indivíduo a assumir uma postura reflexiva e crítica perante a vida em que vive.

Chamando atenção para a vontade minguante, dialoga com os valores da tradição. Ele expõe a ideia de Deus, que ultrapassa todo e qualquer limite de tempo, dando um olhar sobre tudo que já está determinado, perenizado e sem mudança. 
O tempo é nada, não é levado a sério, ele não é real. A própria história aparece sem nenhum sentido, mas, com a morte de Deus, deseja retornar ao sentido da terra e do tempo; e deste último não nos devemos afastar nem ultrapassar o devir das coisas, o perecimento dessas, a contínua mudança. A crença em Deus reflete a caricatura do homem vingativo, que embute na história as forças decadentes, ao mesmo tempo em que essa crença quer fixar as doutrinas do uno, do imóvel, negando o devir. Não é por acaso que faz a crítica a toda vida fraca, que, muitas vezes, é vista sob o olhar das filosofias cristãs, que tomam a renúncia e a compaixão como valores superiores. Se a vida é vontade de potência ${ }^{9}$ e é essa a sabedoria que traz aos discípulos, seu móvel é sempre a superação, a dominação, a luta e a criação de novos valores condizentes com a vida. E isso pode ser bem visualizado na seção " $\mathrm{Da}$ superação de si”. Portanto, todo criador deve querer sua redenção através da dor, do sofrimento. Contudo, essa vontade de nada é apresentada na figura de Deus, do divino, do transcendental, no que é eterno, e as imagens do martelo, da construção e da atividade são negligenciadas.

O que move a questão da criação e da própria superação não é um pensar vingativo, hostil ao mundo e à vida, mas a superação que busca a vontade ativa que esteja distante das ideias teológicas e metafísicas. A superação, ao contrário, deve voltar-se para o movimento, para o devir. Nesse sentido, o saber deve estar envolvido com a vida, com a crítica, com a afirmação, com a superação do pensamento vingativo. É com esse saber que Zaratustra quer mostrar a sua selvagem sabedoria para os niilistas, os corpos cansados, no sentido de educar seus pares para estarem distantes de tais inspirações e, por outro lado, reeducarem-se a si mesmos diante dessas tentações; esse é um dos desafios dos seus ensinamentos. A educação de Zaratustra não pode ser vista desvinculada do seu aprendizado e dos seus ensinamentos; aliás, esses dois componentes caminham conjuntamente.

A relação que o educador Zaratustra dispõe com seus discípulos é tentar alertá-los para longe das concepções de vida que inspiram o cansaço, a não criação e a não atividade. Até nesse momento, ele aspira a imitar os seus pares na prudência,

9. No texto de Clark (2001), esta autora afirma que, antes de a vontade de potência aparecer em Assim falou Zaratustra, ela se mostra primeiramente em uma direção psicológica. Nesse texto, há três distinções a respeito da vontade de potência no pensamento de Nietzsche: a psicológica, a biológica e a doutrina ontológica, destacando os níveis psicológico e ontológico. Na perspectiva psicológica, trata da motivação do humano, há uma perspectiva restrita e ampla. A doutrina ontológica é qualificada como força do universo. No mesmo artigo, há um esforço para compreender a doutrina em seu status epistemológico. Sobre a questão epistemológica, segue uma esquemática em que a doutrina possa ser metafísica, científica ou mítica. 
à distância, para incitá-los a procurar os cumes. A sua visão é destacar a possibilidade de viver uma vida fora da vingança e, nesse sentido, procura compartilhar com eles essa responsabilidade, para que façam esse trabalho consigo mesmos. No momento em que Zaratustra leva a eles tal compreensão sobre a vida, a sua relação não só demanda ousadia, medo, engano, perigo, mas uma grande e profunda responsabilidade para ambos. No entanto, essa relação entre educador e discípulo, para esclarecer, foi constituída pelo respeito e não pela imposição, pelo comando. Isso fica claro, no final do capítulo anterior, quando Zaratustra pede que os discípulos o questionem, pois longe dele querer meros ouvintes cativados. Isto é, de certa forma, respeita a capacidade de o outro poder guiar a si mesmo. Reforçando a leitura dos "discursos", o educador Zaratustra inspira a capacidade mais profunda dos seus pares para manterem-se a distância da vida cansada. Provoca-os para serem cada vez mais profundos em um mundo que perdeu de vista a profundidade da vida. Esse é um exercício formativo que demanda trabalho, sensibilidade e, acima de tudo, respeito consigo mesmo.

Sendo assim, destacam-se algumas seções em que se pode visualizar a denúncia de Zaratustra, para se entender que tipo de movimento educativo deve ser feito. Fala sobre os "compassivos", acusa-os de gerarem a dor, o sofrimento, deleitando-se em sua compaixão: são indivíduos sem pudores, e contra eles mostra a figura do nobre, esse tipo que procura estar acima da compaixão, já que, para Zaratustra, há um mal-entendido em tudo que se vê como compaixão, pois favores não geram gratidão, como dizem, mas apenas ressentimentos. Por isso, ele sente vergonha do sofredor e da sua própria vergonha, e diz que, quando o ajudou, foi, sobretudo, tentado contra a sua avidez. Os valores da compaixão, no fundo, só querem esconder a dominação, ao mesmo tempo em que aquele que se utiliza dela tem um olhar curvado para baixo, que busca o decadente, o pobre, o insignificante, para oferecer sua solidariedade, mas, no fundo, quer fazer bem para si mesmo. A compaixão quer dispor-se de si mesma, do seu próprio amor. Para livrar-se da compaixão, é necessário declinar de todos os sentimentos menores. Por isso, é preciso livrar-se inclusive dos "sacerdotes", que são tomados pelo maior dos redentores, pois o redentor dos sacerdotes, pelo qual se pensou a grande redenção, não deixou, sobretudo, de gerar falsos sonhos. Portanto: "E de homens ainda maiores do que todos os redentores ainda tereis de ser redimidos [...]" Zaratustra retorna à ideia do super-homem, mas para ele "jamais houve um super-homem" (NIETZSCHE, 2011, p. 89). Criticando 
a moral cristã e todos os seus efeitos, fala daqueles que se chamam "virtuosos", que fazem da terra o sofrimento, a dor, como pagamento de um paraíso celestial.

"Os virtuosos" põem a ilusão, a premiação e o castigo como redentores de todas as coisas, pois querem ser recompensados com a eternidade. Mas não existe paga nem pagador, a virtude é sua própria recompensa. Pretende que suas palavras rasguem o fundo dessas almas e quer retirar o véu que está por cima de todas as palavras como "vingança", "castigo", "prêmio", "recompensa". Ensina que se deve amar as próprias virtudes como a mãe ama um filho, ou seja, sem interesses. Zaratustra, ao contrário de muitos, não deseja partilhar o poço, a chama e o fruto com a "gentalha". Com ela tudo fica enfraquecido, sem vida, sem prazer e sem gosto, pois a vida é associada à inimizade, à morte, a cruzes e aos sacrifícios. Assim, demarca seu nojo, tanto pela gentalha do passado como pela do presente. A crítica zaratustriana procura rasgar as bases de todos os valores tradicionais, sendo contra eles que o tipo nobre deve se impor.

Os tempos cheiram mal, "como um aleijado que se tornou surdo, cego e mudo: assim vivi muito tempo, para não viver com a gentalha do poder, da escrita e do prazer" (NIETZSCHE, 2011, p. 93). Libertou-se desse asno, dessa negatividade, dessa sujeira, subindo, voando para as alturas, pois: "Meu próprio nojo me deu asas e o dom de descobrir água? Em verdade, tive de voar a mais elevada altura para reencontrar o manancial do prazer!" (NIETZSCHE, 2011, p. 93). Deram-lhe forças divinatórias para achar a grande nascente do prazer, porém somente nas alturas a gentalha não pode compartilhar o mel. Para Nietzsche, como diz Keith AnsellPearson (1997, p. 22),

o perigo é que a sociedade perderá de vista a importância da cultura [...]. A sociedade torna-se composta por um rebanho de "últimos-homens e mulheres" preocupados apenas com a "felicidade" (compreendida no sentido da satisfação dos desejos materiais) e que não podem conceber nada mais elevado ou mais nobre além (über) de si próprio.

Por isso, faz questão de denunciar a pobreza do seu tempo, na tentativa de que aqueles que possam ser criadores, legisladores, possam caminhar distante dos homens que são adoradores da felicidade imediata.

E assim retorna à ideia de que o homem, para tornar-se grande, deve subir, exercer sua capacidade heroica de vida. Relatando sobre si mesmo, diz que o seu coração sofreu, sentiu o asno bem próximo de si. E, mesmo no declínio, há também 
o sentimento da plenitude: "com frias fontes e bem-aventurada quietude: vinde, amigos, para que mais bem-aventurada ainda se torne a quietude!" (NIETZSCHE, 2011, p. 94), ou seja, ele se reporta ao que aprendeu ou desaprendeu, na sua experiência, para se tornar e, com isso, se permite ensinar, dialogar sobre aquilo que parece em si já superado. Do ponto de vista educacional, Zaratustra, como educador, quer destacar, denunciar essa vida medíocre, e, por outro lado, quer abrir uma janela para que seja visto tal declínio, a fim de que seus pares não sejam sucumbidos por ele - é isso que ele também espera do tipo criador. Busca mostrar todo esse cenário para que eles possam visualizar a vida, os valores, a partir de novas medidas. Porém, é interessante notar que, para Zaratustra, somente cada um pode buscar a sua própria medida, a sua própria lei, o seu próprio discernimento.

Ele entende, diante desses ensinamentos, que os vingativos, aqueles que pregam a sua doutrina da vida, são apenas doces "tarântulas", pois jamais sentiram verdadeiramente a dor, a carne e o sangue do seu próprio viver, não conseguiram sentir o que há de mais fundo e mais íntimo, que é o viver em sua particularidade, em sua individualidade, com sua força mais íntima e vital, que é querer tornar-se, cuidar de si mesmo, ser forte o suficiente para viver na desigualdade. Cada um, cada indivíduo forte deve conservar esses ventos mais altos e profundos, indicando que esses superficiais jamais poderão compreender o sentido da vida de sua filosofia, pois não a experimentaram. Para viver sobre o solo do não idêntico, é necessário fazer a ruptura com tudo que parece ser vulgar, pondo por terra todo o ideal da vida moderna que implique a igualdade ${ }^{10}$, no espírito comum. Isso ele também espera do

10. A ideia de igualdade criticada por Zaratustra refere-se não só às filosofias políticas modernas, mas ao ideal cristão e às próprias filosofias metafísicas que detêm a universalização. Ele quer retomar o propósito da singularidade, perdida na massificação e na alienação desses discursos, pois aquele que deseja o afastamento, precisa, sobretudo, retomar o seu si mesmo, e para isso é fundamental que o indivíduo sinta tudo que lhe é próprio, intrínseco, particular. A singularidade e a individualidade vistas por Nietzsche são aquelas do aristocrata, que cultiva os valores do homem guerreiro. $O$ pretexto da igualdade se fortalece na perspectiva da moral cristã, segundo a qual todos os homens são criaturas de Deus e, portanto, somos todos iguais, até na lei, o que é mera ilusão, pois Nietzsche entende que essa ética universalista é somente uma arena venenosa em que querem destruir as potencialidades humanas. As tarântulas querem efetivamente negar a diferença, o divergente, e submeter o indivíduo à teia da igualdade, que na verdade não existe. Os pregadores da igualdade não são profundos. Como deveriam ser, se são vingativos? Não conseguem ver a vida com alegria e leveza, mas como o fariam se não conseguem criar? Ir para além do que são? Os sintomas desses indivíduos são a fraqueza, a conservação, próprias dos espíritos mais fracos, pois as tiranias do semelhante e do igual danificam o que seja particular. Acham-se sempre no direito de castigar e aprisionar o diferente, daí ele chamar a atenção para que se suspeite de todo aquele que é poderoso e que fala sobre a justiça. Nietzsche se mostra, mais uma vez, como um filósofo extemporâneo, pois, naquele momento, já percebia que a justiça 
tipo criador. Ele leva para os discípulos esse campo reflexivo, para que eles façam a travessia sobre essa perspectiva decadente.

Ao pronunciar-se sobre a sua perspectiva de justiça, fala dos famosos sábios, que são os moradores da cidade, que gostam de servir o povo, sem que possam conhecer o que seja grandeza e altura. Retoma a perspectiva da solidão, elogia os espíritos livres, que sabem dizer não, pois eles são verazes.

A sua vontade de leão é faminta, violenta, solitária, livre da vontade servil, ela é destemida. Os espíritos livres sabem viver longe do povo e encontrar-se nas mais geladas nascentes. E termina essa seção, dizendo que a sua selvagem sabedoria corre no mar que treme na impetuosidade do vento. Quem pode ouvi-lo, compreendê-lo? Serão os discípulos? Ou não? Quem pode despachar essas dúvidas? Quem ainda está preocupado com este fio delicado da educação ou da reeducação? Quem se preocupa em discutir os valores? Quem ainda está preocupado com questões de ordem existencial e filosófica?

Vê-se que Zaratustra, paulatinamente, vai conduzindo seu pensamento para outra ordem de interpretação. Se o indivíduo tem que exercer o martelo criador, se tem que retirar-se do asno, da negatividade, agora ele tem que exercer sua potência criadora. Essa é a grande sabedoria, e aqui, mais uma vez, a afirmação criadora se mostra não só pela metáfora do martelo trazida por Zaratustra, mas também diante da vontade de potência. É para esse sentido que ele pretende despertar os

estava travestida do poder, na vontade de castigar, de policiar, de torturar, sob a farsa do seu aparelho. No fundo, aqueles que se dizem iguais querem escamotear e negligenciar a diferença; sob essa perspectiva, a sociedade está envolvida por um espírito vingativo. Como, pode-se indagar, os pregadores da igualdade podem querer falar da vida, se toda a sua defesa é para o contrário da vida? Para sentir e experimentar a vida em elevação, é necessária a experiência mais profunda da singularidade, pois somos capazes de contar e fazer histórias vivendo a experiência do viver, do fazer, dentro da perspectiva de criar e de libertar. Contudo, isso é negado em prol do ideal de universalidade, deixando, cada vez mais, os indivíduos desprovidos de si mesmos. É essa particularidade, essa intimidade, essa profundidade do viver, aquilo que é somente do próprio indivíduo e de mais ninguém que os pregadores da igualdade querem aniquilar e desprezar, enfatizando, por outro lado, a massificação, a diluição do individual. No fundo, todos esses vingativos são conduzidos por um pensamento metafísico, desejando uma moral comum, uma lei comum. Zaratustra diz que o seu grande amor se abre a favor do além-do-homem, dos afirmadores e criadores. Com eles pode-se pensar a multiplicidade, a contradição e a desigualdade, pois tudo isso faz parte da intimidade do criador. É essa disposição, vista sob a figura do super-homem, que Zaratustra opõe ao alinhamento do progresso, desse fim determinado, pois a vontade quer sempre criar, mas também é sempre contradição. Ergue esse debate a partir dos valores humanos, do embate entre os valores bem e mal, pobreza e riqueza, ligando-os à luta em torno da vida. Por isso é possível entender porque fala dos valores bem e mal. Tudo que é decadente nega a vontade criadora e em seu favor lança-se numa vida fraca, sem dominação de si mesmo. 
discípulos, mesmo sem saber se eles serão tocados por essa sabedoria. Apresenta essa alternativa para o indivíduo, precisamente na seção da "Superação de si". Porque só assim o homem pode superar o que há de lodo em si mesmo, pode avançar sobre si mesmo no exercício contínuo de afirmação. É exatamente essa sabedoria que ele expõe para seus "discípulos". Para o exercício da vontade de potência, é necessário que a vontade avance sobre qualquer tipo de cansaço e sonolência. Para isso Zaratustra parece alertar quando descreve todas as coisas postas aqui.

4 .

Com essas reflexões, Zaratustra nos leva a pensar que não se pode criar a si mesmo mergulhado por forças vingativas e do cansaço. Aquele que deseja ser senhor de si, antes de tudo, precisa exercitar a sua mais potente vontade de criar. Essa vontade também percorre o movimento de autossuperação, perpassada pela destruição incessante dos próprios movimentos criativos.

Nenhuma inércia é possível no seio dessa dinâmica da vontade criadora que fomenta uma imbricação de criar/destruir. Contra os pressupostos fundamentais da moralidade cristã, Zaratustra fomenta uma objeção contra a compaixão, os valores de rebanho, e entende que a vida, diante de sua plenitude, requer toda uma criação, ultrapassando sempre a si mesmo. Pois, como diz Giacoia Júnior (1997, p. 167),

se o movimento perpétuo da vida é de ultrapassamento e auto-superação, então esse criar para além do já alcançado tem que ser inseparável da destruição e do sofrimento. Para tal compreensão da vida, faz-se necessário sobretudo a coragem para aventurar-se em todos os abismos e labirintos da alma

Ora, sabe-se que essa perspectiva é repugnante para aqueles que são dogmáticos, conservadores, exigentes de uma vida utilitária, adaptativa. Para Nietzsche, a vida não é um conjunto da natureza pacificadora e acomodada; antes, ela é guerra, luta, força, movimento, desequilíbrio. Sendo assim, a vida não é uma situação de indigência e de fraqueza, ela é efetivamente exuberância, combate e potência. $\mathrm{O}$ que isso pode nos ensinar? $\mathrm{O}$ que isso pode nos educar? Sem um modelo de leitura, cada um encontre suas próprias margens, suas próprias entradas no labirinto filosófico de Zaratustra. 


\section{REFERÊNCIAS}

ANSELL-PEARSON, Keith. Nietzsche como pensador politico: uma introdução. Tradução de Mauro Gama e Claudia Martinelli Gama. Rio de Janeiro: Jorge Zahar, 1997.

CLARK, Maudemarie. Nietzsche's doctrines of the will to power. Oxford: University Press, 2001.

FINK, Eugin. A filosofia de Nietzsche. Tradução de Joaquim Loureço Duarte Peixoto. Lisboa: Presença, 1988.

GIACOIA JÚNIOR, Oswaldo. Labirintos da alma: Nietzsche e auto-supressão da moral. Campinas, SP: Editora da UNICAMP, 1997.

MACHADO, Roberto. Zaratustra: tragédia nietzscheana. Rio de Janeiro: Jorge Zahar, 1997.

NIETZSCHE, Friedrich. Além do bem e do mal: prelúdio a uma filosofia do futuro. Tradução, notas e posfácio de Paulo César de Souza. São Paulo: Companhia das Letras, 1992.

. Genealogia da moral: uma polêmica. Tradução, notas e posfácio de Paulo César de Souza.

São Paulo: Companhia das Letras, 1998.

. Assim falou Zaratustra: um livro para todos e para ninguém. Tradução, notas e posfácio de Paulo César de Souza. São Paulo: Companhia das Letras, 2011.

SALAQUARDA, Jörg. A concepção básica de Zaratustra. Tradução de Scarlett Marton. Cadernos Nietzsche - Grupo de Estudos Nietzsche, São Paulo, n. 2, p. 17-30, 1997.

\section{SOBRE A AUTORA}

Maria dos Remédios de Brito é graduada em Pedagogia e em Filosofia pela Universidade Federal do Pará (UFPA), tem mestrado e doutorado em Filosofia da Educação pela Universidade Metodista de Piracicaba (UNIMEP) e é Pós-Doutora em Filosofia da Educação pela Universidade Estadual de Campinas (UNICAMP). Atualmente é professora associada I da Universidade Federal do Pará. E-mail:mrdbrito@hotmail.com

Recebido em 16 de dezembro de 2015 e aprovado em 28 de janeiro de 2016. 